\title{
Los programas de cumplimiento en materia ambiental y el problema del impacto del cambio de circunstancias en su eficacia
}

\section{The environmental compliance programs and the impact of changing circumstances on their efficacy problem}

\author{
William García Machmar ${ }^{1}$ \\ Francisca Soto Monteverde ${ }^{2}$
}

Los programas de cumplimiento ambiental corresponden a un incentivo al cumplimiento de las normas e instrumentos de carácter ambiental, mediante los cuales el presunto infractor se obliga a cumplir un conjunto de metas y acciones para corregir su conducta antijurídica y hacerse cargo de los efectos negativos derivados de su incumplimiento al medio ambiente. En caso de advenir circunstancias no previstas durante la fase de ejecución de estos programas, se afectará primordialmente la eficacia del programa aprobado, de manera que el acto administrativo que aprueba un Programa de cumplimiento debe ser corregido para adecuarse a la realidad. La Superintendencia del Medio Ambiente podrá elegir entre declarar su inva-
An environmental compliance programme is an incentive to comply with environmental regulations, in which the presumed offender is mandated to fullfill a number of goals and actions, in order to correct their unlawful behaviour as well as manage any consequential negative environment impact. In the case of unforeseen circumstances during the execution fase of this programme, the efficacy of it is likely to be affected, therefore, a correction must be made for adapting the programme to reality. The Environmental Watchdog may choose between declaring its invalidity, its decline, modify the administrative act that approved the programme, or declare its noncompliance.

\footnotetext{
1 Magister en Derecho (LLM) New York University. Magíster en Derecho Universidad de Chile. Licenciado en Ciencias Jurídicas y Sociales Universidad de Chile. Correo electrónico: wgarciamachmar@gmail.com. Dirección postal: Cienfuegos 41, Santiago, Región Metropolitana, Chile.

2 Magister en Derecho y Política Ambiental (LLM) University College. London. Licenciada en Ciencias Jurídicas y Sociales Universidad de Chile. Correo electrónico: fsotomonteverde@ gmail.com. Dirección postal: Cienfuegos 41, Santiago, Región Metropolitana, Chile.
}

Artículo recibido el 19 de abril de 2021 y aceptado el 13 de junio de 2021. 
lidez, su decaimiento, modificar el acto administrativo que aprobó el programa, o bien, declarar su incumplimiento.

Palabras clave: cumplimento ambiental, programa de cumplimiento ambiental, cambio de circunstancias, eficacia.
Keywords: environmental compliance, environmental enforcement undertaking, changing of circumstances, efficacy.

\section{Introducción}

Este artículo presenta un estudio de los Programas de Cumplimiento Ambiental como un instrumento de incentivo al cumplimiento de la normativa ambiental presente en los procedimientos administrativos sancionadores que sustancia la Superintendencia del Medio Ambiente. Particularmente, se examina el fenómeno del cambio de circunstancias de hecho, una vez aprobado un programa de este tipo, y las actitudes que puede tomar la autoridad ambiental ante tal escenario desde una perspectiva del Derecho Administrativo. Para ello, se emplea una metodología doctrinal, entendiendo esta como "aquel tipo de investigación que provee una exposición sistemática de las reglas que gobiernan una particular categoría legal, analiza las relaciones entre reglas, explica las áreas que presentan dificultades, y quizás predice futuros desarrollos [...] envuelve análisis de jurisprudencia, disponer, ordenar y sistematizar proposiciones legales y el estudio de instituciones legales" 3 . Particularmente, se ha consultado literatura especializada sobre Derecho Administrativo y Derecho Ambiental, tanto de culturas legales pertenecientes a tradiciones de derecho continental como anglosajón, así como una revisión de la jurisprudencia emanada de los Tribunales Ambientales de Chile y la Corte Suprema, para aquellos casos en que el objeto del litigio consistió en la impugnación de un acto administrativo que aprueba o rechaza un programa de cumplimiento, o bien, que declaró su cumplimiento o incumplimiento, y, además, la sentencia se haya referido directa y sustancialmente a los programas de cumplimiento. Se estudió el periodo de tiempo correspondiente a marzo de 2013 hasta enero de 2021, lo cual totaliza 24 fallos, accediendo a estos a través de las páginas web de cada uno de los Tribunales Ambientales. Se argumenta que para analizar el fenómeno del cambio de circunstancias durante la ejecución de un Programa de Cumplimento, debe atenderse fundamentalmente al criterio de eficacia porque es aquel que debe ocuparse específicamente de los efectos del incumplimiento ambiental imputado al presunto infractor, tanto respecto de la normativa ambiental, como de los efectos negativos generados al medio ambiente. En consecuencia, las actitudes que puede tomar la Superintendencia del Medio Ambiente ante el cambio de circunstancias podrán ser las siguientes: declarar la invalidez del acto por haberse incurrido en algún vicio de legalidad; declarar el decaimiento del

3 HUtCHinson \& DunCan 2012, 101. Citado por: ISHWARA, 2019, 145. 
acto por haberse producido hechos sobrevinientes que lo hacen imposible; modificar el acto; o bien, podrá declarar el incumplimiento de este.

\section{Los planes de cumplimiento en general}

Una manera para aproximarse al Derecho Ambiental en una determinada cultura legal es a través del estudio de las distintas "arquitecturas" o estrategias regulatorias que se han adoptado para enfrentar los problemas ambientales. Como explica la literatura especializada, el término arquitectura permite mostrar los pilares básicos de las normas ambientales, regulación y gobernanza, lo cual permite visualizar sus conexiones y entender la completitud del sistema jurídico ambiental ${ }^{4}$. Mientras que las normas ambientales refieren a las leyes dictadas por el Parlamento, la regulación es un concepto más amplio, que incluye formas de control social más flexibles, imaginativas e innovadoras, y que incumbe a los gobiernos, los mercados, empresas y terceros ${ }^{5}$. Por otra parte, la dogmática sobre regulación le define como:

el intento sostenido y focalizado de alterar el comportamiento de otros de acuerdo con estándares u objetivos con la intención de producir un(os) resultado(s) general(es) identificado(s), lo cual puede requerir mecanismos de establecimiento de estándares, levantamiento de información y modificación de comportamiento6.

Por último, vinculado él, se haya la noción de gobernanza, que para algunos autores equivale a un concepto amplio de regulación ${ }^{7}$, y dice relación con un cambio de paradigma para gobernar, donde se enfatiza el rol de las redes compuestas por los actores públicos y privados y, en menor grado, el sector de las organizaciones voluntarias o cuerpos intermedios ${ }^{8}$. En este aspecto, se ha señalado que la gobernanza ambiental implica la colaboración de los diversos actores provenientes del sector privado, público y organizaciones no gubernamentales, quienes comportándose de manera mancomunada hacia un objetivo común -o bien, negociando-, esperan alcanzar metas mucho más ambiciosas que si hubieran actuado actuando de manera individual9. Así, la doctrina sobre "nueva gobernanza" pretende explicar un cambio desde la tradicional forma de intervención estatal, esencialmente jerárquica y desde arriba hacia abajo, hacia una nueva forma que incluye nuevos actores $^{10}$ y que promueve el empleo de herramientas legales flexibles,

\footnotetext{
4 Gunningham 2009, 180.

5 lbíd., 181.

6 BLACK 2006, 11.

7 PRESTON 2019, 720 y LeE 2014, 81-82. En este artículo no se pretende hacer una revisión exhaustiva sobre la literatura de gobernanza, con todo, se sugiere consultar: RHODES 1996, 652-667; ARMSTRONG y KiLPATRICK 2006, 649 y ss.

8 Fisher et al. 2019, 277.

9 Gunningham 2009, 203.

10 Fisher et al. 2019, 277.
} 
en contraposición a aquellas que establecen mandatos concretos, como las reglas de comando y control.

Aun cuando se discute en la literatura sobre el uso apropiado de los términos gobernanza y regulación, nosotros compartimos la tesis expuesta por Preston, en el sentido de entender que un concepto amplio de regulación puede emplearse para ciertos fines como equivalente al de gobernanza, toda vez que el fin ulterior de una u otra consiste en influir o modificar el comportamiento humano para la protección ambiental o el desarrollo sustentable ${ }^{11}$. Así entonces, lo esencial para nuestro argumento es examinar un fenómeno caracterizado por la irrupción de estrategias dentro del ámbito de la regulación ambiental, que incluye la participación de regulados, la comunidad afectada por intervenciones al medio ambiente y la colaboración entre estos y la Administración para la satisfacción del interés público.

Una expresión de este cambio de paradigma en la legislación chilena corresponde a los Programas de Cumplimiento (en adelante, "PdC"), el cual se introdujo al ordenamiento jurídico mediante el artículo 42 de la LOSMA ${ }^{12}$ y es en una vía para evitar la sanción administrativa, consistente en un compromiso adoptado por el presunto infractor de nomas o instrumentos de carácter ambiental, para ejecutar satisfactoriamente una serie de acciones y metas dirigidas a corregir su comportamiento antijurídico, como así también hacerse cargo de los efectos negativos al medio ambiente generados por el incumplimiento, si corresponde. Lo anterior refleja un cambio de perspectiva para tratar el incumplimiento ambiental porque dota a la autoridad ambiental de mayor flexibilidad para cumplir con su deber represivo, requiriendo necesariamente la colaboración del regulado ${ }^{13}$, y también de terceros afectados por la intervención al medio ambiente, al estar habilitados para actuar dentro del procedimiento administrativo sancionador como interesados, cuando se cumplan los requisitos para ello ${ }^{14}$. Por eso que en su génesis se concibió

\footnotetext{
11 PRESTON 2019, 720.

12 La ley orgánica de la Superintendencia del Medio Ambiente (LOSMA) se encuentra contenida en el artículo segundo de la Ley $N^{\circ}$ 20.417, cuerpo legal que a partir del año 2010 modificó sustancialmente la institucionalidad ambiental.

13 Algunos autores han desarrollado la idea de flexibilidad y la colaboración como rasgos del modelo de la "regulación responsiva". Según esta estrategia, la exigencia de cumplimiento de la ley por parte de los órganos públicos a los regulados descansa en una pirámide, donde los mecanismos más indulgentes se ubican en la base y los más rigurosos en la punta, tales como la revocación y suspensión de autorizaciones. Este método asume que el principal objetivo de la exigencia del cumplimiento de la ley es asegurarlo y permite un enfoque de "paso a paso", donde el regulador es capaz de acercarse al infractor mediante medidas informales, y menos intrusivas, antes de aplicar sanciones. Pedersen 2013, 321. En Chile, Soto plantea que únicamente la aprobación por parte de la SMA de los programas de gradualidad corresponde a un ejemplo de regulación responsiva, porque "no existe densidad regulatoria al efecto y, en consecuencia, la discrecionalidad del regulador será mayor", mientras que para la aprobación de los PdC deben concurrir presupuestos normativos para su aprobación. SОто 2016, 209-210.

14 V. gr. artículo 21 de la LOSMA.
} 
como un ejemplo de instrumento de incentivo al cumplimiento de la normativa ambiental ${ }^{15}$.

A nuestro juicio, es evidente que el fin último del $\mathrm{PdC}$ reside en la protección ambiental, en el entendido que el propósito de cualquier regulación ambiental reside en modificar la conducta humana en el sentido de impactar positivamente en la calidad o cantidad de bienes ambientales ${ }^{16}$. En esta línea de pensamiento, la doctrina nacional ha expuesto que:

la función de protección ambiental, en un sentido amplio, constituye una reacción por parte del Estado frente a la amenaza o peligro de un daño o deterioro ambiental actual, pero también importa una responsabilidad duradera y permanente para asegurar las bases de la vida de las futuras generaciones ${ }^{17}$.

De este modo, puede afirmarse que los PdC son una manifestación del principio de prevención, en el sentido que es preferible evitar los daños ambientales a remediarlos, o bien, en el caso que se constaten impactos o daños, evitar que estos se propaguen ${ }^{18}$. Lo anterior, por cuanto el presunto infractor debe hacerse cargo de todos los efectos negativos al medio ambiente derivados del incumplimiento ${ }^{19}$, lo cual implica, entonces, que se funde tanto su ocurrencia, como no ocurrencia de estos. Así entonces, no basta con la mera invitación y consecutivo compromiso del presunto infractor para volver al cumplimiento de la normativa infringida, sino que el objeto último es la protección del medio ambiente a través de acciones y metas que garanticen la indemnidad del medio ambiente. En esta línea, por lo demás, se ha pronunciado consistentemente la jurisprudencia ${ }^{20}$. Adicionalmente, es esencial el rol de la cooperación entre el regulado y la Administración para la constitución del un PdC, pues el contenido de dicho mecanismo toma forma y depende significativamente del diálogo entre la autoridad ambiental y el presunto infractor en, por ejemplo, las reuniones de asistencia al cumplimiento;

\footnotetext{
15 Biblioteca del Congreso Nacional de Chile 2010, Mensaje.

16 LIVERMORE 2007, 316.

17 BerMúdez 2014b, 26.

18 de SAdeleer 2002, 61.

19 Artículos 7 y 9 del Decreto Supremo N³0, de 2013, del Ministerio del Medio Ambiente.

20 Corte Suprema. Barría con Superintendencia del Medio Ambiente (2017), Co 6 (Rol N 67.4182106) y Pastene con Superintendencia del Medio Ambiente (2018), C 22 (Rol N 11.485-2017). En el mismo sentido: Primer Tribunal Ambiental. Comunidad Indígena Atacameña de Peine con Superintendencia del Medio Ambiente (2019), C 224 (Rol No R-17-2019); Segundo Tribunal Ambiental. León con Superintendencia del Medio Ambiente (2020), C 49 (Rol N R-199-2018); Pastene con Superintendencia del Medio Ambiente (2020), C 24 (Rol N R-170-2018); Velozo con Superintendente del Medio Ambiente (2018), C 66 (Rol NR-153-2017); Sociedad Química y Minera de Chile S.A. con Superintendencia del Medio Ambiente (2018), C 14 (Rol N R-1602017); López con Superintendencia del Medio Ambiente (2018), Co 19 (Rol N R-163-2016); León con Superintendencia del Medio Ambiente (2017), C 44 (Rol N R-132-2016); Ecomaule S.A. con Superintendencia del Medio Ambiente (2017), C 42 (Rol N R-112-2016); Pastene con Superintendente del Medio Ambiente (2017), C 23 (Rol No 104-2016); Compañía Minera Nevada SpA con Superintendencia del Medio Ambiente (2016), C ${ }^{\circ}$ 10. (Rol Nº R-75-2015).
} 
además, para la aprobación de un $\mathrm{PdC}$ es esencial la provisión de antecedentes técnicos que realice el presunto infractor por cuanto se encuentra en una posición de sujeto calificado frente a la actividad que realiza y solo así podrá garantizarse que las acciones y metas son aptas para volver al cumplimiento y hacerse cargo de los efectos negativos provocados como resultado de su incumplimiento normativo. En este sentido, el profesor Jorge Bermúdez ha concebido a la cooperación como un principio en materia ambiental, que en el caso del ejercicio de la potestad sancionatoria se manifiesta precisamente en el mecanismo del PdC, resultando en "una co-determinación del contenido de la declaración que se contiene en el acto" 21 .

\section{Definición legal}

Los PdC están definidos en el inciso segundo del artículo 42 de la LOSMA como "el plan de acciones y metas presentado por el infractor, para que, dentro de un plazo fijado por la Superintendencia, los responsables cumplan satisfactoriamente con la normativa ambiental que se indique" (Ley $\left.N^{\circ} 20.417,2010\right)$. La misma redacción es repetida en la letra g) del artículo 2 del decreto supremo N³0, de 2013, del Ministerio del Medio Ambiente, que Aprueba Reglamento sobre Programas de Cumplimiento, Autodenuncia y Planes de Reparación (en adelante, "DS 30/2013"). De la definición legal es posible identificar los elementos constitutivos del PdC, los cuales son: i) Contenido (plan de acciones y metas); ii) Sujeto (el infractor, quien presenta el plan); iii) Plazo (tiempo dentro del cual debe cumplirse el programa) y; iv) Finalidad (cumplimiento de la normativa medioambiental)22.

Los programas de cumplimiento se caracterizan, entonces, en primer lugar, por corresponder a un instrumento de incentivo al cumplimiento de la normativa medioambiental, tal como también sucede con los mecanismos de autodenuncia y los planes de reparación ${ }^{23}$. En segundo lugar, constituyen una solución o un término alternativo del procedimiento sancionador ambiental llevado por la Superintendencia del Medio Ambiente (en adelante, "SMA"). Cuando se aprueba el $\mathrm{PdC}$ el procedimiento sancionatorio se suspende $\mathrm{y}_{\text {, }}$ eventualmente, se extinguirá por un acto administrativo que no decidirá su objeto principal, esto es, la existencia de responsabilidad infraccional ${ }^{24}$. Aquello ha llevado a sostener a la jurisprudencia medioambiental que solo el PdC, como instrumento de incentivo al cumplimiento, constituye una alternativa a la sanción administrativa frente a la inobservancia normativa ${ }^{25} \mathrm{o}$

\footnotetext{
21 Bermúdez 2014b, 53.

22 Segundo Tribunal Ambiental. Sociedad Vinícola Miguel Torres S.A. con Superintendencia del Medio Ambiente (2016), C $C^{\circ}$ 21. (Rol N R-68-2015).

23 Corte Suprema. Víctor Alejandro Barría Oyarzo con Superintendencia del Medio Ambiente (2017). C 6 (Rol No 67.418-2016).

${ }^{24}$ Corte Suprema. Pastene con Superintendencia del Medio Ambiente (2018), C $C^{\circ}$ 18. (Rol $\left.\mathrm{N}^{\circ} 11.485-2017\right)$.

25 Segundo Tribunal Ambiental. Compañía Minera Nevada SpA con Superintendencia del Medio Ambiente (2016), Co 9. (Rol No R-75-2015).
} 
un método de término anormal de los procedimientos sancionatorios sustanciados por la $\mathrm{SMA}^{26}$. Asimismo, la jurisprudencia ha observado que en caso de existir incompatibilidad entre el contenido de la resolución de calificación ambiental y el PdC, debe preferirse la aplicación de este último puesto que, de lo contrario:

implica, no sólo desconocer el espíritu de la solución colaborativa, sino derechamente desatender su tenor literal, omitiendo la satisfacción de objetivos reparatorios que el titular del proyecto se ha auto impuesto, y que constituyen la esencia de la institución en cuestión ${ }^{27}$.

En tercer lugar, en los PdC destaca el espíritu colaborativo entre la autoridad y el infractor, lo cual conlleva beneficios recíprocos entre estos ${ }^{28}$, así como la asignación al infractor del costo (o responsabilidad) de los efectos producidos con motivo de la infracción. En cuarto lugar, en virtud del artículo

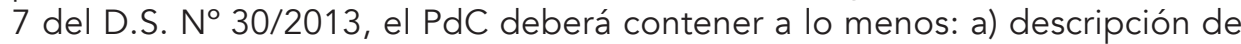
los hechos, actos $u$ omisiones que constituyen la infracción en que se ha incurrido, así como de sus efectos; b) plan de acciones y metas que se implementarán para satisfacer la normativa ambiental y para reducir o eliminar los efectos producidos por el incumplimiento; c) plan de seguimiento; d) información técnica y de costos estimados del $\mathrm{PdC}^{29}$. Corresponderá a la SMA verificar el cumplimiento de los requisitos del $\mathrm{PdC}$, pudiendo exigir al titular la presentación de los antecedentes suficientes para adoptar una correcta decisión ${ }^{30}$. Por último, la satisfacción plena e integral de los PdC constituye una forma extraordinaria o anormal de poner término al procedimiento administrativo sancionador en materia ambiental ${ }^{31}$.

\section{Delimitación del concepto}

\section{a. No es un contrato de Derecho Público}

La Administración del Estado está habilitada para celebrar diferentes tipos de contratos. Así, puede haber contratos sometidos al derecho privado (como los contratos de prestación de servicios "a honorarios"), o contratos sometidos al derecho público (como el contrato de suministro de que trata la

\footnotetext{
${ }^{26}$ Corte Suprema. Ecomaule S.A. con Superintendencia del Medio Ambiente (2018), C ${ }^{\circ}$ 11. (Rol $\left.\mathrm{N}^{\circ} \mathrm{N}^{\circ} 8.456-2017\right)$.

27 Corte Suprema. Ecomaule S.A. con Superintendencia del Medio Ambiente (2018), C ${ }^{\circ}$ 13. (Rol $N^{\circ} N^{\circ}$ 8.456- 2017). Vid.: Segundo Tribunal Ambiental. Ecomaule S.A. con Superintendencia del Medio Ambiente (2017), CC 58 y ss. (Rol No R-112-2016).

28 Segundo Tribunal Ambiental. Ecomaule S.A. con Superintendencia del Medio Ambiente

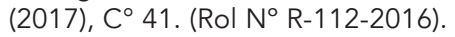

29 OSSANDÓN 2015, 237-242.

30 Segundo Tribunal Ambiental. Pastene con Superintendente del Medio Ambiente (2017), C 40 (Rol No 104-2016).

31 Ossandon 2015, 202-203.
} 
Ley $\left.\mathrm{N}^{0} 19.886\right)^{32}$. En el caso de los contratos de derecho administrativo, Bermúdez señala que son:

un acuerdo de voluntades entre un organismo de la Administración del Estado que actúa dentro de su giro y tráfico propio administrativo y en ejercicio de sus competencias específicas y un particular u otro organismo público que actúa como particular y no dentro de sus competencias específicas, que tiene por objeto la satisfacción de necesidades públicas, produciendo entre ellas derechos y obligaciones ${ }^{33}$.

De lo recientemente expuesto surge la primera diferencia entre un contrato de Derecho Público y un $\mathrm{PdC}$ toda vez que el primero constituye un acuerdo de voluntades, donde al menos una de las partes debe ser un órgano de la Administración del Estado, mientras que el PdC es un acto unilateral de la Administración, pues si bien materializa una situación de colaboración entre esta y el infractor, la decisión de aceptar su procedencia recae exclusivamente en la SMA, mientras que el infractor solo concurrirá con su voluntad al inicio del procedimiento, proponiendo un $\mathrm{PdC}^{34}$.

Por otra parte, el PdC no constituye un contrato de Derecho Público puesto que, estos contratos buscan la obtención de algún tipo de prestación a favor de la Administración, característica que no se aprecia en el caso de los PdC. En dicho sentido, la jurisprudencia ambiental ha indicado que:

lo que caracteriza a estos instrumentos, es la colaboración entre las partes y que estos establecen beneficios recíprocos para ellas. [...] el programa de cumplimiento tiene como objetivo último la protección del medio ambiente [...] Por consiguiente, le corresponde competencialmente a la SMA la facultad de decidir su aprobación, de acuerdo con lo dispuesto en el artículo 3 letra r) de la LOSMA ${ }^{35}$.

\section{b. No son sanciones administrativas}

i. El programa de cumplimiento es una forma de impedir la sanción administrativa

La terminación "normal" del procedimiento administrativo sancionador sustanciado por la SMA se produce con la dictación de una resolución que, pronunciándose acerca de los cargos formulados contra el presunto infractor y sus descargos, así como los medios de prueba allegados al proceso, determine la absolución o la sanción, según sea el caso. Sin embargo, para el caso de los PdC, precisamente su aprobación altera el curso normal del procedi-

\footnotetext{
32 También en nuestro derecho se habla de "convenios", como en el caso de la encomendación de gestión (artículo 37 del decreto con fuerza de Ley N 1, de 2000, del Ministerio Secretaría General de la Presidencia).

33 Bermúdez, 2014a, 239.

${ }^{34}$ Segundo Tribunal Ambiental. Compañía Minera Nevada SpA con Superintendencia del Medio Ambiente (2016), C 44 (Rol N R-75-2015).

35 Ibíd., C० 10.
} 
miento administrativo sancionador. De conformidad al inciso cuarto del artículo 42 de la LOSMA, una vez aprobado el PdC se producirá la suspensión del procedimiento sancionatorio. Es decir, no habrá un acto administrativo que declare la responsabilidad administrativa del infractor ni imponga alguna de las sanciones ya indicadas, ni habrá absolución, sino que:

implica la extinción de aquél, no tanto porque decida o resuelva sobre el fin propio del procedimiento sancionador sino porque lo hace desaparecer como materia a resolver. Aquel fin, que no es otro que la apreciación de la existencia o no de una infracción, es materia sobre la que la terminación convencional no se pronuncia ni puede pronunciarse y cuya decisión en vía administrativa viene precisamente a impedir ${ }^{36}$.

En palabras del Primer Tribunal Ambiental, "de ser exitoso la ejecución de $[\mathrm{PdC}]$, se reemplazará la resolución sancionatoria de termino, por una en virtud de la cual se tenga por cumplido satisfactoriamente el programa"37. Sobre el particular, la jurisprudencia ha destacado la finalidad y objetivos tenidos a la vista para la incorporación de los mecanismos de incentivos al cumplimiento en la Ley $\mathrm{N}^{\circ} 20.417^{38-39}$.

En suma, la forma tradicional de reacción de la Administración frente a incumplimientos es la imposición de sanciones, pero tratándose de los PdC podemos apreciar que estos constituyen mecanismos que precisamente suspenden tal procedimiento sancionatorio, por ende, debe descartarse que tengan la naturaleza jurídica de una sanción administrativa, aun cuando su génesis reside un procedimiento administrativo sancionador. Dicha génesis queda de manifiesto en la decisión del Primer Tribunal Ambiental, al sostener que la consulta indígena que contemplan el Convenio $N^{\circ} 169$, de la Organización Internacional del Trabajo y el Decreto Supremo N66, de 2013, del Ministerio de Desarrollo Social no tiene cabida en el proceso de formulación y aprobación de un $\mathrm{PdC}$, toda vez que este se enmarca en un procedimiento sancionatorio y porque el legislador no ha expresamente incluido dicha consulta en la LOSMA, ni en el reglamento ${ }^{40}$.

\footnotetext{
36 LORENTE 2008, 165.

37 Primer Tribunal Ambiental. Comunidad Indígena Atacameña de Peine con Superintendencia del Medio Ambiente (2019), C० 9. (Rol NR-17-2019).

38 Segundo Tribunal Ambiental. Sociedad Vinícola Miguel Torres S.A. con Superintendencia del Medio Ambiente (2016), CC 14 y 19. (Rol NR-68-2015).

39 Segundo Tribunal Ambiental. Compañía Minera Nevada SpA con Superintendencia del Medio Ambiente (2016). C $\mathrm{C}^{\circ}$ 17. (Rol NR-75-2015).

40 Primer Tribunal Ambiental. Asociación Indígena Aymara Salar de Coposa con Superintendencia del Medio Ambiente (2019), CC 37 y 47 (Rol N R-25-2019); Comunidad Indígena Atacameña de Peine con Superintendencia del Medio Ambiente (2019), CC ${ }^{\circ}$ 51-52 (Rol N R-17-2019); Comunidad Indígena Aymara de Quillagua y otro con Superintendencia del Medio Ambiente (2020), CC $C^{\circ}$ 164-166. (Rol N R-21-2019).
} 


\section{ii. Es una medida u orden de restablecimiento de la legalidad}

La propuesta de un PdC se produce una vez que la SMA ha formulado cargos en contra del supuesto infractor, con el objeto de brindarle una oportunidad para que este pueda restablecer su conducta hacia la legalidad. Atendido que el procedimiento sancionador se suspende por la aprobación del PdC, es posible afirmar que en Chile, conceptualmente se trata de manifestaciones diversas.

La doctrina española ha señalado que mediante las medidas de restablecimiento de la legalidad la Administración, ante la realización de una conducta prohibida por ley, restablece el orden vulnerado, ordenando su paralización o incluso la reparación ${ }^{41}$. Así, típicamente una medida de restablecimiento de la legalidad es la obligación de reponer las cosas al estado anterior a la infracción ${ }^{42}$, que es justamente lo que hacen los PdC. Toda vez que no son sanciones no están limitadas por los mismos principios que limitan el ejercicio de la potestad sancionadora, como la culpabilidad ${ }^{43}$. Ello ha sido confirmado por parte de la judicatura medioambiental ${ }^{44}$. De esta manera, el legislador le ha entregado al infractor una herramienta para enmendar su obrar contrario a Derecho, pudiendo inclusive ser eximido de su responsabilidad administrativa si da cumplimiento cabal del PdC.

\section{c. No son un modo de responsabilidad ambiental}

El PdC no es el medio idóneo para hacer efectiva la responsabilidad ambiental. Por de pronto, porque no se dirige a reparar -ni en naturaleza ni en dinero- un daño causado a una persona determinada, como consecuencia de una conducta negligente ${ }^{45}$. Con todo, hay que reconocer que puede existir impacto recíproco entre ambas técnicas, por cuanto el $\mathrm{PdC}$ obliga a hacerse cargo de los efectos de la infracción, pero son instrumentos jurídicos diver$\operatorname{sos}^{46}$. Enseguida, el legislador ha creado instrumentos especiales para hacer efectiva la responsabilidad ambiental y lograr la reparación que, en virtud del principio de competencia, no son de libre elección para la Superintendencia.

\section{i. $\quad$ Acción de responsabilidad}

Lo programas de cumplimiento son una forma de exigir al infractor que asuma las consecuencias de su obrar, pero distinta de la contenida en los artículos 51 y siguientes de la ley $N^{\circ}$ 19.300. Este artículo 51 prescribe que "Todo el que culposa o dolosamente cause daño ambiental responderá del

41 Huergo 2007, 249.

42 Ibíd., 255.

43 Ibíd., 265.

44 Segundo Tribunal Ambiental. Compañía Minera Nevada SpA con Superintendencia del Medio Ambiente (2016), CC 7 y 14. (Rol N R-75-2015).

45 Segundo Tribunal Ambiental. Velozo con Superintendente del Medio Ambiente (2018), $C^{\circ} 72$. (Rol N R-153-2017). En este trabajo se sigue la definición de daño ambiental, y por lo tanto de responsabilidad ambiental, empleada por Barros 2006, 787 y ss.

46 Huergo 2007, 267. 
mismo en conformidad a la presente ley" y el artículo 53 confiere "acción para obtener la reparación del medio ambiente dañado, lo que no obsta al ejercicio de la acción indemnizatoria ordinaria por el directamente afectado".

Cabe preguntarse si existe incompatibilidad en la aprobación de un programa de cumplimiento y la acción de reparación del artículo 53. La ley solo establece dicha restricción respecto de los planes de reparación: "No procederá la acción para obtener la reparación del medio ambiente dañado cuando quien cometió el daño ejecutó satisfactoriamente un plan de reparación aprobado por la Superintendencia del Medio Ambiente".

Por lo demás, la jurisprudencia ambiental ha establecido que "la aprobación de un programa de cumplimiento no impide que, paralelamente, se persiga la responsabilidad mediante la acción de reparación de daño ambiental, ni tampoco configura un elemento necesariamente vinculante para dicho procedimiento" $"$.

Igualmente, se ha discutido si el presunto infractor que haya sido acusado en la formulación de cargos de cometer una infracción gravísima porque haya causado daño ambiental, de acuerdo con el articulo 36 número 2 letra a) de la LOSMA, se encuentra habilitado para presentar un PdC. Al respecto, el Primer Tribunal Ambiental ha señalado que "no es razonable aumentar las exigencias establecidas en la LOSMA para la procedencia de un PdC, no correspondiendo a la SMA limitar el acceso a un incentivo al cumplimiento ambiental como lo es el PdC, cuyos impedimentos ya se encuentran establecidos expresamente en la LOSMA"48.

Con todo, las exigencias impuestas en el juicio de reparación medioambiental deberían tener en consideración las medidas ejecutadas en virtud de estos programas, ya que la eliminación o reducción de los efectos negativos probablemente no estarán presentes en el medio ambiente a la época de resolverse estos procesos judiciales. Luego, aunque son instrumentos diferentes, tienen una influencia recíproca.

\section{ii. Vínculo con los Programas de reparación}

El artículo 43 dispone que "Sin perjuicio de las sanciones administrativas que se impongan, una vez notificada la resolución de la Superintendencia que pone término al procedimiento sancionador, el infractor podrá presentar voluntariamente ante ella una propuesta de plan de reparación", por consiguiente, su presentación no procede en la época temprana de la formulación de cargos, ya que este instrumento busca más bien que el infractor asuma las consecuencias de su conducta ya una vez sancionado por la SMA. No obstan-

\footnotetext{
47 Segundo Tribunal Ambiental. Carrasco con Superintendencia del Medio Ambiente (2017), $C^{\circ}$ 24. (Rol N R-116-2016).

${ }^{48}$ Primer Tribunal Ambiental. Asociación Indígena Aymara Salar de Coposa con Superintendencia del Medio Ambiente (2019), C 93 (Rol No R-25-2019). En el mismo sentido: Segundo Tribunal Ambiental. Carrasco con Superintendencia del Medio Ambiente (2017), CC 22, 23 y 24. (Rol $\left.N^{\circ} \mathrm{R}-116-2016\right)$.
} 
te, esta clase de instrumentos sí presenta beneficios para el infractor, ya que su ejecución satisfactoria (aprobada por la SMA) extinguirá la acción de reparación medioambiental previamente comentada.

Como se puede apreciar, la presentación y aprobación de un programa de cumplimiento y de un programa de reparación son incompatibles temporalmente, ya que uno y otro pueden proponerse a la SMA en oportunidades totalmente distintas. El primero procede al momento de la formulación de cargos y el segundo una vez finalizado el procedimiento sancionatorio, de manera que es imposible su proposición conjunta o coetánea.

\section{El acto administrativo aprobatorio de un plan de cumplimiento}

De acuerdo con las clasificaciones tradicionales de los actos administrativos, a continuación se caracterizará, en términos generales, a la resolución que se pronuncia sobre la propuesta de un PdC.

\section{a. Es un acto administrativo desfavorable}

La clasificación más importante de los actos administrativos es la que atiende a su contenido según si es favorable o desfavorable. La importancia de esta clasificación es que tratándose de los actos favorables -constitutivos o declarativos de derechos o intereses- la ley impide su revocación de oficio. Ahora bien, la resolución que se pronuncia sobre la propuesta de un programa de cumplimiento puede ser entendida como un acto positivo, porque acoge una propuesta del particular, y porque suspende la tramitación del procedimiento sancionador. Creemos que esa aproximación es errónea. En rigor, si se atiende al contenido del acto administrativo es un acto de contenido negativo o desfavorable porque impone cargas o deberes sobre el interesado ${ }^{49-50}$. Por lo tanto, como se verá más adelante, es un acto que puede ser modificado o revocado, dadas las condiciones necesarias.

\section{b. Es un acto administrativo constitutivo}

Es un acto configurador o constitutivo de nuevas obligaciones ${ }^{51}$. No se limita a "declarar" las obligaciones, deberes y cargas ya preconfiguradas en la normativa medioambiental52, así, la resolución puede imponer órdenes y prohibiciones que innovan en la esfera jurídica del destinatario.

\section{c. Es un acto administrativo necesitado de colaboración}

Además, es un acto administrativo necesitado de colaboración. Si bien es un acto unilateral de la Administración, tiene como supuesto el que el

\footnotetext{
49 Gallego y Menéndez 2001, 65.

50 La clasificación puede estar complejizada por el hecho de que la resolución puede producir efectos frente a terceros interesados que no se apersonan en el procedimiento administrativo, o también porque ante el destinatario directo producen efectos mixtos. BOCANEGRA 2006, 50-51.

51 lbíd., 54-55.

52 Gallego y Menéndez 2001, 69.
} 
interesado -presunto infractor- haya efectuado una propuesta previa a la Superintendencia ${ }^{53}$. Y es que, la judicatura medioambiental ha señalado que la facultad exclusiva del regulado para presentar el PdC se funda en que, su aprobación le impone cargas que requieren de una manifestación de voluntad previa de este ${ }^{54-55}$.

Dicha colaboración se manifiesta también en el principio de contradictoriedad que prevé el artículo 10 de la LBPA, permitiéndose al interesado "en cualquier momento del procedimiento, aducir alegaciones y aportar documentos u otros elementos de juicio", y como contrapartida, en el deber de asistencia al regulado de la SMA que contempla el artículo 3 letra u) de la LOSMA, en relación con el artículo 3 del DS 30/2013. Sobre ello, la jurisprudencia ha determinado que el deber de asistencia se satisface, entre otros, mediante la convocatoria a reuniones, reportes de observaciones a versiones anteriores de $\mathrm{PdC}$ presentado por el titular del proyecto ${ }^{56}$.

\section{d. Es un acto administrativo discrecional}

\section{i. $\quad$ No existe un derecho a obtener un pronunciamiento favorable}

Finalmente, es un acto discrecional, no reglado. El interesado que hace una propuesta, cumpliendo con los requisitos legales, no tiene un derecho a que este sea aprobado. La Superintendencia puede decidir, por razones de política represiva, continuar con el procedimiento sancionador, o aprobar el programa de cumplimiento, según lo que en cada momento estime que promueve de mejor manera el cumplimiento ambiental (el interés público).

Sin embargo, en cuanto acto discrecional está sometido al control de ciertos elementos que deben concurrir, no pudiendo "exigir requisitos o imponer criterios que no estén expresamente regulados en la normativa" ${ }^{57}$. En este sentido es reveladora la afirmación de Gallego: "[L]a vinculación de la actividad de la Administración al Derecho en estos casos en que la norma le otorga competencias discrecionales se consigue mediante el contrapeso que supone la imposición del deber de motivar y justificar suficientemente esas decisiones" ${ }^{15}$.

En términos muy simples es posible afirmar que el ejercicio de las potestades discrecionales se puede controlar, a través del control de su motivación ${ }^{59}$,

\footnotetext{
53 Ibíd., 70-71.

54 Segundo Tribunal Ambiental. Ecomaule S.A. con Superintendencia del Medio Ambiente (2017), C 45 (Rol NR-112-2016).

55 Bocanegra 2006, 60-61.

56 Primer Tribunal Ambiental. Interchile S.A. con Superintendencia del Medio Ambiente (2018), $C^{\circ} 18$ (Rol N R-4-2018).

57 Segundo Tribunal Ambiental. Compañía Minera Nevada SpA con Superintendencia del Medio Ambiente (2016), C $\mathrm{C}^{\circ} 11$. (Rol N R-75-2015).

58 Gallego y Menéndez 2001, 85.

59 CoRdero 2015, 86-95.
} 
sobre la base de dos criterios: i) Por una parte, los tribunales ambientales pueden examinar la proporcionalidad, que como juicio de control se integra de tres sub-juicios: necesidad, idoneidad y proporcionalidad en sentido estricto de la medida en cuestión). ii) Por otra parte, pueden examinar la razonabilidad del acto, es decir, la coherencia interna de la decisión y análisis del proceso de tomarse la decisión.

\section{ii. Criterios de aprobación}

La SMA debe observar 3 criterios mínimos para la aprobación de un PdC, estos son: a) integridad, b) eficacia, c) verificabilidad ${ }^{60}$, los cuales se encuentran contenidos en el artículo 9 letras a), b) y c) respectivamente, del DS 30/2013.

En virtud del criterio de integridad, la SMA debe verificar que las acciones y metas propuestas en el PdC deben referirse a todos los hechos infraccionales y sus efectos, los cuales deben coincidir con los cargos que se han formulado en contra del infractor en un determinado procedimiento sancionatorio ${ }^{61}$, pues en caso contrario, existiría falta de coherencia y congruencia entre la resolución que aprueba el PdC y aquella que formula los $\operatorname{cargos}^{62}$. En concordancia, se ha enfatizado en que no constituye una facultad de la SMA, ni del regulado determinar qué cargos se incorporan al programa ${ }^{63}$. En un sentido amplio, el criterio de integridad implica que "debe existir una cierta coherencia entre la descripción de los hechos constitutivos de infracción y la forma de subsanarlos con las acciones y metas propuestas"64. Según el Segundo Tribunal Ambiental implica que:

el infractor describa los efectos que se derivaron de los hechos, actos u omisiones que fueron parte de la formulación de cargos, ya que solo de esta forma se pueden conocer las consecuencias directas de las infracciones en el medio ambiente. Para el caso que estime que no concurren efectos, deberá señalar las razones de su ausencia, con un nivel de detalle que dependerá de las características del caso concreto, lo que deberá ser refrendado por la SMA para permitir su aprobación ${ }^{65}$.

Desde ya se aprecia la importancia de este criterio, pues solo sí se describen de manera completa y fundada (primordialmente mediante evidencia

\footnotetext{
60 Segundo Tribunal Ambiental. Sociedad Vinícola Miguel Torres S.A. con Superintendencia del Medio Ambiente (2016), C C 24. (Rol No R-68-2015).

61 Segundo Tribunal Ambiental. Sociedad Vinícola Miguel Torres S.A. con Superintendencia del Medio Ambiente (2016), C ${ }^{\circ} 25$ (Rol No R-68-2015); Carrasco con Superintendencia del Medio Ambiente (2017), C 29 (Rol No R-116-2016); Tercer Tribunal Ambiental. Barría con Superintendencia del Medio Ambiente (2016), C 7 (Rol N R-36-2016).

62 Tercer Tribunal Ambiental. Sepúlveda y Otros con Superintendencia del Medio Ambiente (2016), Co 18 (Rol N R-40-2016).

${ }_{63}$ Segundo Tribunal Ambiental. Compañía Minera Nevada SpA con Superintendencia del Medio Ambiente (2016), C $C^{\circ} 36$ y C 44 (Rol No R-75-2015).

64 OSSANDÓN 2015, 244.

${ }^{65}$ Segundo Tribunal Ambiental. Pastene con Superintendencia del Medio Ambiente (2020), Cons. 22 (Rol N R-170-2018).
} 
técnico-científica), podrá evaluarse si las acciones propuestas cumplen con el criterio de eficacia a la luz de la protección ambiental. En este sentido, la jurisprudencia ambiental ha acentuado que el examen de los efectos al ambiente derivados del incumplimiento ambiental debe considerar las especiales características del lugar donde se emplaza el proyecto, por ejemplo, su valor ambiental y su valor para comunidad indígena, -lo cual denota la complejidad de los problemas ambientales ${ }^{66}$ - y cómo todos los elementos del problema ambiental detectado deben ser considerados por el presunto infractor a la hora de presentar su PdC:

[...] es un requisito esencial para aprobar un PdC, que tanto la CMIDC [Compañía Minera Doña Inés de Collahuasi] como la SMA, identifiquen y aborden íntegramente todos los efectos, así como todas las acciones y metas vitales y plausibles para volver al cumplimiento ambiental, resguardando con ello el bien protegido del acuífero, la vertiente Jachucoposa y sus cuerpos lagunares de la cuenca del Salar de Coposa, como si interacción con la biodiversidad y las zonas de pastoreo ancestral de la Asociación Aymara de Coposa; más aun siendo este un Sitio Prioritario para la Conservación y en un escenario de cambio climático ${ }^{67}$.

Por su parte, el criterio de eficacia implica que en el PdC "el infractor no solo tiene la obligación de volver al cumplimiento ambiental, sino que, juntamente con ello, debe hacerse cargo de los efectos de las infracciones cometidas." 68 La doctrina nacional ha estimado que este criterio de aprobación es el de "mayor complejidad" de los tres ${ }^{69}$, por cuanto debe considerar el binomio "infracción-efecto", donde los efectos podrán ser apreciados con un mayor grado de discrecionalidad ${ }^{70}$ por la autoridad ambiental, dado que el reglamento establece que las acciones y metas del programa deben, entre otras cuestiones, "contener y reducir o eliminar" los efectos de los hechos que constituyen la infracción. De este modo, la Administración podrá considerar cumplido el requisito de eficacia tanto porque las acciones propuestas por el titular del proyecto contengan y reduzcan los efectos de la infracción, o bien, porque los elimina.

El tercer criterio de aprobación es el de verificabilidad, en cuya virtud, las metas y acciones del programa deben contemplar mecanismos que permitan acreditar su cumplimiento ${ }^{71}$. La Superintendencia deberá observar el

\footnotetext{
66 FISHER 2013, 349-351.

67 Primer Tribunal Ambiental. Asociación Indígena Aymara Salar de Coposa con Superintendencia del Medio Ambiente (2019), Cons. 228. (Rol NR-25-2019).

68 Segundo Tribunal Ambiental. Sociedad Vinícola Miguel Torres S.A. con Superintendencia del Medio Ambiente (2016), Cons. 26 (Rol N R-68-2015); Velozo con Superintendente del Medio Ambiente (2018), Cons. 86 y 87. (Rol N R-153-2017).

69 Hervé y Plumer 2019, 36.

70 lbíd.

71 Segundo Tribunal Ambiental. Sociedad Vinícola Miguel Torres S.A. con Superintendencia del Medio Ambiente (2016), Cons. 27 (Rol N R-68-2015).
} 
plan de seguimiento y su cronograma de acciones y metas para dar por acreditado el cumplimiento de este criterio $^{72}$.

\section{e. Es un acto administrativo de trámite. Impugnabilidad}

De acuerdo con el artículo 15 LBPA los actos administrativos impugnables son los actos definitivos, es decir, los que deciden la cuestión de fondo (artículo 41 LBPA). En cambio, en contra de los actos de trámite solo procederán recursos bajo circunstancias calificadas, a saber, "cuando determinen la imposibilidad de continuar un procedimiento o produzcan indefensión." 73 Bajo lo indicado corresponde definir a qué categoría corresponde la resolución que aprueba o rechaza un programa de cumplimiento, sobre todo considerando que su aprobación por la SMA produce la suspensión del procedimiento sancionatorio.

Al respecto, la jurisprudencia judicial ambiental ha reiterado que corresponde a un "acto trámite cualificado", ya que no pone término al procedimiento administrativo, lo suspende, pero a la vez la ley hace imposible su prosecución. Ha establecido que "la resolución que se pronuncia sobre un programa de cumplimiento constituye un acto de mero trámite cualificado, en cuanto decide sobre el fondo del asunto planteado, pudiendo causar indefensión... Es un acto recurrible -mediante recurso de reposición- y objeto de control judicial"74.

En virtud de lo reseñado, proceden contra la resolución que aprueba o rechaza un programa de cumplimiento, tanto los recursos administrativos como el de reposición, así como el reclamo de ilegalidad de competencia de los Tribunales Ambientales (artículo $17 N^{\circ} 3$ ley N²0.600 en relación con artículo 56 LOSMA), aun cuando no estemos ante un acto definitivo, puesto que si bien el acto en cuestión no produce el término del procedimiento administrativo, puede impedir su continuación o provocar indefensión.

Ahora bien, en cuanto a la legitimación activa para reclamar la resolución que aprueba o rechaza un $\mathrm{PdC}$, se ha asentado en la jurisprudencia que dicha calidad se vincula con el procedimiento administrativo sancionador que

\footnotetext{
72 Ossandon 2015, 246.

73 CoRdero 2015, 254.

74 Segundo Tribunal Ambiental. Sociedad Contractual Minera Corporación de Desarrollo del Norte con Superintendencia del Medio Ambiente (2017), Cons. 18 (Rol No R-82-2015 [acumulada con R-100-2016 y R-119-2016]); León con Superintendencia del Medio Ambiente (2017), Cons. 11 (Rol No R-132-2016); Velozo con Superintendente del Medio Ambiente (2018), Cons. 68 (Rol $N^{\circ}$ R-153-2017). En el mismo sentido: Primer Tribunal Ambiental. Asociación Indígena Aymara Salar de Coposa con Superintendencia del Medio Ambiente (2019), C 28 (Rol No R-25-2019); Comunidad Indígena Atacameña de Peine con Superintendencia del Medio Ambiente (2019), Cons. 29 (Rol No R-17-2019). De la opinión contraria es Jorge Ossandón, quien sostiene que es improcedente el recurso de reposición, pues tal como se desprende de su definición legal, tal recurso se aplica solo en aquellos casos en que se sanciona, luego el PdC no tendría naturaleza de sanción. También dispone que, igualmente es improcedente el recurso jerárquico, y solo podría interponerse la reclamación ante el tribunal ambiental. OsSANDON 2015, 253-260.
} 
le ha dado origen, conforme a la lectura de los artículos $18 \mathrm{~N}^{\circ} 3$ de la Ley $N^{\circ} 20.600$ y 56 de la LOSMA. De igual modo, es fundamental lo dispuesto por el artículo 21 de la LOSMA, el cual prevé que, si un procedimiento administrativo sancionador se iniciare por denuncia, entonces el denunciante tendrá para todos efectos legales la calidad de interesado en el respecto procedimiento. De este modo, la jurisprudencia ha entendido que el denunciante detendrá la calidad de directamente afectado, por lo tanto, de legitimación activa para reclamar la resolución que apruebe un $\mathrm{PdC}^{75} \mathrm{o}$ aplique una sanción ${ }^{76}$.

También podrían ejercerse otras formas de revisión de la legalidad del acto administrativo a través de solicitudes de invalidación (artículo 53 LBPA) o el recurso extraordinario de revisión (artículo 60), o incluso una petición ante la Contraloría General de la República solicitando su pronunciamiento sobre la ilegalidad del acto.

\section{f. Es un acto administrativo sujeto a plazo}

De acuerdo con el artículo 42 inciso sexto el plazo es un elemento o cláusula necesaria 77 de la resolución que aprueba un PdC. El artículo 9 inciso tercero DS 30/2013 es más explícito al señalar que "la resolución establecerá los plazos dentro de los cuales deberá ejecutarse el programa". En este sentido el $\mathrm{PdC}$ es un acto administrativo con efectos prolongados que establecen una relación duradera ${ }^{78}$. Es posible afirmar que se trata de un plazo discrecional, pues la ni la ley ni el reglamento fijan una duración estricta. Tampoco señalan rangos mínimos o máximos. Se trata, por lo tanto, de un elemento discrecional del acto administrativo.

Ahora bien, pueden señalarse los siguientes criterios que deberán guiar su determinación. Ante todo, de los criterios de eficacia y verificabilidad se desprende que el plazo debe ser el necesario para lograr el cumplimiento de la normativa ambiental, buscando que sea el más corto posible. Por ejemplo, se ha fallado que:

el deber de apoyo de la SMA a los administrados, sobre la revisión de programas de cumplimiento, deben ser razonables, concretos y proporcionales al tipo, tiempo y envergadura del proyecto de que se trate, siendo cada caso revisado y asistido en su mérito [...] siendo un proyecto cuya ejecución es acotada (18 meses), lógico es asumir que los abordajes de incumplimiento, como los instrumentos alternativos deben ser

\footnotetext{
75 Corte Suprema. Pastene con Superintendencia del Medio Ambiente (2018), Cons. 29 (Rol $N^{\circ}$ 11.485-2017). En el mismo sentido: Segundo Tribunal Ambiental. León con Superintendencia del Medio Ambiente (2020), Cons. 8-9 (Rol Nº R-199-2018); Carrasco con Superintendencia del Medio Ambiente (2017), Cons. 9 (Rol No R-116-2016); León con Superintendencia del Medio Ambiente (2017), Cons. 34 (Rol No R-132-2016); Pastene con Superintendente del Medio Ambiente (2017), Cons. 9 (Rol No 104-2016).

76 Segundo Tribunal Ambiental. Cruz con Superintendencia del Medio Ambiente (2014), Cons. 10-12 (Rol N R-6-2013). Al respecto, consultar: Hunter 2014, 259-270.

77 Gallego y Menéndez 2001, 110.

78 BOCANEGRA 2006, 56-57y 92.
} 
revisados y zanjados al menor plazo posible a fin que el proyecto vuelva a su condición de normalidad según lo exigido por la RCA ${ }^{79}$.

Enseguida, la ley prohíbe que el PdC tenga una finalidad "manifiesta-

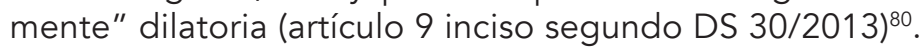

Finalmente, toda vez que el plazo de prescripción de la responsabilidad administrativa del presunto infractor es de tres años, podría pensarse que ese debe ser el plazo máximo de duración de un PdC. De este modo, si el presunto infractor propone un plazo de ejecución del PdC superior a tres años, la SMA debiera rechazarlo. Sin embargo, si estimamos que la resolución que aprueba un $\mathrm{PdC}$ suspende el procedimiento administrativo sancionador, entonces, la prescripción permanece interrumpida hasta que no se dicte la resolución que declara cumplido (o incumplido el $\mathrm{PdC}$ ). Esta interpretación permite, además, que el $\mathrm{PdC}$ se adapte a la realidad de los diferentes procesos productivos que enfrenta cada industria.

\section{Impacto del cambio de circunstancias}

Durante la ejecución del PdC pueden acontecer circunstancias de hecho que no fueron previstas al momento de la formulación este. Sobre concepto de previsibilidad, la dogmática civilista lo ha desarrollado como presupuesto del juicio de culpabilidad en el marco de la responsabilidad extracontractual, indicado que:

[l]a previsibilidad no hace referencia a un fenómeno psicológico, sino a aquello que debió ser previsto, atendidas las circunstancias. Como ocurre en general con los elementos del juicio de negligencia, la previsibilidad se valora en abstracto, considerando el discernimiento de una persona diligente ${ }^{81}$.

Así entonces, la previsibilidad es un rasgo que permite distinguir si se está frente a un eximente de responsabilidad, como lo es el caso fortuito. En este mismo sentido Tapia considera que la imprevisibilidad en su entendimiento contemporáneo y relativo invoca "a una representación mental y anticipada de que ciertos hechos pueden ser las probables consecuencias de ciertas causas", de lo que se sigue que su apreciación debe efectuarse en abstracto, sobre la base del modelo de una persona diligente, en consideración a sus circunstancias ${ }^{82}$. Tales categorías jurídicas pueden servir a nuestro caso de estudio pues el advenimiento de nuevas circunstancias durante la ejecución del PdC puede resultar en la imposibilidad absoluta de continuar

\footnotetext{
79 Primer Tribunal Ambiental. Interchile S.A. con Superintendencia del Medio Ambiente (2018), Cons. 19 (Rol N R-4-2018).

80 Segundo Tribunal Ambiental. Pastene con Superintendente del Medio Ambiente (2017), Cons. 26 (Rol No 104-2016); Primer Tribunal Ambiental. Asociación Indígena Aymara Salar de Coposa con Superintendencia del Medio Ambiente (2019), Cons. 93 (Rol N R-25-2019).

81 BARROS 2006, 90.

82 TAPIA 2020, 30.
} 
con su ejecución, tal como acontece con la fuerza mayor o caso fortuito, o bien, pueden resultar en que aun cuando no sea imposible la ejecución del plan, este se deba realizar conforme a acciones que no fueron previstas en el $\mathrm{PdC}$ aprobado, afectando la eficacia de este.

Existen diferentes factores que hacen del $\mathrm{PdC}$ un instrumento sensible al cambio de circunstancias. Primero, como ya se ha dicho, la falta de certeza acerca de los efectos de la infracción ambiental, especialmente, la visión parcial que se tiene en ese momento de cómo se desencadenaron los cursos causales. Segundo, el hecho de que el instrumento se ejecutará a lo largo de un determinado plazo que puede llegar a ser de varios años de duración. Tercero, las asimetrías de información.

\section{La eficacia como criterio esencial en los Planes de Cumplimiento}

En principio, el acto administrativo que aprueba el programa de cumplimiento vincula no solo a su destinatario -el presunto infractor que lo propusosino que también a la $\mathrm{SMA}^{83}$. Con todo, evidentemente no se trata de que exista una especie de "cosa juzgada" del acto administrativo. Este es esencialmente revisable: "como medio de configuración orientado al futuro debe más bien adaptarse a las circunstancias cambiantes" 84 .

\section{a. Cómo deben enfrentarse los efectos}

En virtud del criterio de eficacia los PdC deben preocuparse específicamente de enfrentar los efectos del incumplimiento ambiental imputado al presunto infractor. En tal sentido, la justicia ambiental ha sostenido que la descripción detallada de los efectos constituye un requisito mínimo de contenido del $\mathrm{PdC}$, cuya ausencia o insuficiencia permite rechazar su procedencia ${ }^{85}$. Por lo mismo es relevante detenerse a explicar cómo deben tratarse los efectos en la resolución que aprueba el PdC. A continuación, haremos algunas recomendaciones, precisamente para optimizar esta dimensión de los planes de cumplimiento, teniendo especial consideración en la necesidad de fundamentar de manera completa y coherente el acto administrativo aprobatorio.

En primer lugar, desde el punto de vista formal, resulta aconsejable que se incluya un considerando especial relativo a los efectos de la infracción, que como ya revisamos se contiene como el criterio de integridad. En segundo lugar, también es útil describir los efectos declarados por el proponente y cómo han sido abordados adecuadamente, a través de un detalle de las acciones. En tal sentido, el infractor deberá señalar los efectos de sus infrac-

\footnotetext{
83 "El acto administrativo como regulación de autoridad debe ser vinculante y duradero, debe obtener estabilidad jurídica. Esto se deriva ya del carácter regulador del acto administrativo, ya que una regulación que fuera disponible a voluntad carecería de sentido y de valor. A la misma conclusión se llega si se tiene en cuenta la función clarificadora y estabilizadora del acto administrativo, que tiene su fundamento, a su vez, en la seguridad jurídica". MAURER 2011, 299.

84 Ibíd., 300.

85 Segundo Tribunal Ambiental. Compañía Minera Nevada SpA con Superintendencia del Medio Ambiente (2016), Cons. 41 (Rol N R-75-2015).
} 
ciones y/o ausencia, realizando una debida justificación de por qué no se han producido estos. Y es que, solo por medio de una adecuada descripción de los efectos se podrá evaluar si las acciones y metas propuestas en el PdC cumplen con la obligación de "reducir o eliminar" dichos efectos ${ }^{86}$.

En tercer lugar, para darle la mayor eficacia al instrumento también resulta recomendable otorgar la oportunidad de subsanar el PDC propuesto. Esta oportunidad permite al titular proponer acciones y metas que sean susceptibles de ser cumplidas, y acentúa la discrecionalidad del instrumento. En el mismo sentido, la Corte Suprema ha dispuesto que la SMA tiene la facultad de complementar los PdC cuando estos no satisfacen los criterios de aprobación, ya individualizados ${ }^{87}$.

En cuarto lugar, es importante destacar que el reglamento supone que los efectos puede que no se eliminen por completo, como ya comentamos más arriba. En efecto, del artículo $9^{\circ}$ letra b) se desprende que un $\mathrm{PdC}$ será eficaz si las acciones y metas se dirigen satisfactoriamente a: i) En relación con la legalidad ambiental: asegurar el cumplimiento de la normativa infringida. Desde luego, esta es una finalidad prospectiva. Existe una infracción imputada y el interesado se compromete en el futuro a cumplir cabalmente. ii) En relación con los efectos de la infracción: ante todo, siempre el PdC debe al menos contener los efectos de los hechos que constituyen la infracción (corresponde al criterio de integridad) y, para ser eficaz, debe contener un plan de acciones y metas que sean aptos para cumplir con la normativa ambiental y medidas para reducir o eliminar los efectos negativos generados por el incumplimiento. No puede tolerarse un $\mathrm{PdC}$ que agrava la situación previa. Sin embargo, es posible que los efectos no puedan eliminarse por completo, por lo que la normativa acepta que un $\mathrm{PdC}$ sea eficaz si: a) Elimina los efectos, siempre que sea posible, o, b) Al menos los reduce, cuando la eliminación no sea posible.

\section{b. Nivel de certeza exigible}

Los PdC, por la etapa en el procedimiento que se plantean, necesariamente tendrán elementos probatorios precarios. No es posible exigirle a los PdC el nivel de certeza que sí se exige a la sanción o al dictamen del instructor ${ }^{88}$. Puesto que la existencia de la infracción solo es probada "superficialmente" la SMA no requiere tener certeza de la infracción para aprobar el $\mathrm{PdC}$, sino que,

\footnotetext{
86 Segundo Tribunal Ambiental. Pastene con Superintendente del Medio Ambiente (2017), Cons. 27 (Rol No 104-2016).

${ }^{87}$ Corte Suprema. Barría con Superintendencia del Medio Ambiente (2017), Cons. 7 (Rol $\mathrm{N}^{\circ}$ 67.418-2106).

${ }_{88}$ Por ejemplo, el Segundo Tribunal Ambiental ha diferenciado el sistema de evaluación de impacto ambiental y el PdC en cuanto a la profundidad del análisis técnico que les son propio, en el entendido que aquel del SEIA es más profundo y robusto que aquel del PdC, porque este último debe presentarse dentro del plazo de 10 días desde la notificación de la formulación de cargos. Segundo Tribunal Ambiental. Sociedad Química y Minera de Chile S.A. con Superintendencia del Medio Ambiente (2018), Cons. 132 (Rol N R-160-2017).
} 
operará en base a la existencia de indicios. Así lo ha dispuesto el Segundo Tribunal Ambiental al señalar que, el incumplimiento de las normas o medidas destinadas a minimizar o eliminar efectos adversos permite presumir que estos se han producido, siendo carga del titular del proyecto desvirtuar aquello ${ }^{89}$.

Con todo, el nivel de certeza exigible es discutible. Por ejemplo, el Primer Tribunal Ambiental ha sentenciado que la autoridad debe considerar el principio precautorio para aquellos casos en que no exista certeza científico-técnica respecto de los efectos al medio ambiente derivados del incumplimiento ambiental90, como fundamento para acoger una reclamación interpuesta en contra de una resolución que aprobó un PdC. Por otro lado, el Segundo Tribunal Ambiental manifestó que es errónea la interpretación de la SMA sobre el nivel de certeza requerido para determinar que el presunto infractor deba hacerse cargo de los efectos derivados del incumplimiento ambiental, porque ello no implica eliminar por completo los espacios de incertidumbre, "sino que hacer un análisis razonable que permita descartar que los efectos principales han sido abordados y cubiertos" 1 .

Es necesario destacar que el razonamiento expuesto por el Segundo Tribunal Ambiental se enmarca en la discusión acerca de si es procedente incluir como acción dentro de un $\mathrm{PdC}$, el ingreso de un proyecto o parte de este al Sistema de Evaluación de Impacto Ambiental para incumplimientos complejos. En el caso expuesto, el Tribunal con sede en Santiago concluyó que dicha acción es procedente, porque de lo contrario, la SMA estaría estableciendo un requisito ajeno a la ley o al reglamento para la procedencia de los $\mathrm{PdC}^{92}$. En cambio, el Primer Tribunal Ambiental, señaló que la acción consistente en el ingreso al SEIA es inidónea para contener, reducir o eliminar los efectos negativos derivados del incumplimiento ambiental, no dándose así cumplimiento a los criterios de integridad y eficacia ${ }^{93}$. A su turno, el Tercer Tribunal Ambiental ha determinado que respecto a si el ingreso al SEIA se llevará a cabo mediante declaración de impacto ambiental o estudio de impacto ambiental, basta la declaración judicial efectuada por el presunto infractor en la audiencia de alegatos para obligarse a la segunda opción ${ }^{94}$.

\footnotetext{
89 Segundo Tribunal Ambiental. Pastene con Superintendente del Medio Ambiente (2017), Cons. 38 (Rol No 104-2016).

90 Primer Tribunal Ambiental. Comunidad Indígena Atacameña de Peine con Superintendencia del Medio Ambiente (2019), Cons. 177-181 (Rol N R-17-2019).

91 Segundo Tribunal Ambiental. Sociedad Química y Minera de Chile S.A. con Superintendencia del Medio Ambiente (2018), Cons. 133. (Rol N R-160-2017).

92 Segundo Tribunal Ambiental. Sociedad Química y Minera de Chile S.A. con Superintendencia del Medio Ambiente (2018), Cons. 135 (Rol N R-160-2017). En el mismo sentido: Segundo Tribunal Ambiental. León con Superintendencia del Medio Ambiente (2020), Cons. 142 (Rol $N^{\circ}$ R-199-2018), oportunidad en que se aprobó como acción y meta de un PdC la consulta de pertinencia de ingreso al SEIA.

${ }_{93}$ Primer Tribunal Ambiental. Comunidad Indígena Atacameña de Peine con Superintendencia del Medio Ambiente (2019), Cons. 177 (Rol No R-17-2019).

94 Tercer Tribunal Ambiental. Corporación Puelo Patagonia con Superintendencia del Medio Ambiente (2016), Cons. 18 (Rol N R 28-2016).
} 


\section{c. Etapas de la ponderación de los efectos}

Es posible distinguir tres etapas en relación con el análisis de los efectos de la presunta infracción ambiental sometida a un PdC: al momento de la formulación de cargos, antes de la aprobación del PdC y durante su vigencia.

\section{i. Al momento de la formulación de cargos}

Al momento de formularse los cargos, existirá prueba indiciaria de la existencia de una infracción. No es posible contar con pruebas concretas, por definición, pues no se ha verificado la etapa de instrucción del procedimiento donde dicha prueba se rinde.

\section{ii. Antes de la aprobación de un PdC}

En primer lugar, toda vez que, con la propuesta que hace el presunto infractor, se abre una fase de colaboración recíproca entre él y la SMA ${ }^{95}$. resulta aconsejable que se efectúen diligencias útiles y suficientes que permitan establecer las infracciones normativas y mitigar sus efectos. En segundo lugar, es importante recordar que una vez que los efectos quedan incorporados en la resolución, la SMA hace propia dicha consideración. Por lo tanto, es aconsejable que la resolución sea explícita en cuanto al conocimiento que se tiene, en ese momento, por parte de la SMA al momento de aprobar el PdC y por qué:

[l]a exigencia de fundamentar una resolución implica que la autoridad debe indicar en su texto, de manera expresa, los motivos o razones que sirven de fundamento a la decisión que en ellos se adopta, siendo '[...] el fin de la fundamentación no es otro que permitir la reproducción del razonamiento utilizado para alcanzar las conclusiones' ${ }^{\prime 96}$

y que

[L]a resolución impugnada carece de la debida fundamentación para justificar, en términos generales, por qué el programa presentado por Minera La Florida Limitada cumplía con los requisitos para ser aprobado, incurriendo con ello la SMA en un vicio de legalidad ${ }^{97}$.

En consecuencia, la falta de motivación en la decisión de la SMA sobre procedencia o cumplimiento de un PdC podrá constituir un vicio de legalidad del acto, si fuese esencial. Además, se exige que la falta de motivación sea manifiesta, y que no se desprenda de otros hechos ${ }^{98}$.

95 Segundo Tribunal Ambiental. Ecomaule S.A. con Superintendencia del Medio Ambiente (2017), Cons. 38 (Rol No R-112-2016).

96 Segundo Tribunal Ambiental. Pastene con Superintendente del Medio Ambiente (2017), Cons. 30 (Rol No 104-2016).

97 Ibíd., cons. 31.

98 Segundo Tribunal Ambiental. Ecomaule S.A. con Superintendencia del Medio Ambiente (2017), cons. 21 (Rol N R-112-2016). 
En tercer lugar, cabe recordar que la resolución aprueba tanto metas como las acciones que llevarán a cumplirlas. Sin embargo, no debe olvidarse que las acciones estarán relacionadas directamente con decisiones que, ante todo, le corresponden a la empresa y que no es responsabilidad de la SMA adoptar una decisión respecto de ellas pues solo indirectamente se relacionan con el cumplimiento de la legalidad ambiental. Por tanto, el análisis de la SMA debiese estar referido a las metas a cumplir.

Finalmente, en relación con la reunión de antecedentes adicionales:

pese a que las observaciones y correcciones de oficio realizadas por la SMA sean una práctica habitual -observada en cerca del $80 \%$ de los casos informados (...) la entidad fiscalizadora no tiene una obligación legal de realizar dichas observaciones o correcciones, encontrándose plenamente facultada para rechazar de plano un programa de cumplimiento, en caso de estimar que este no cumple los criterios de aprobación ${ }^{99}$.

\section{iii. Después de aprobado un PdC}

Una vez aprobado un PdC puede ocurrir que el desenvolvimiento de los efectos de la infracción sea distinto a los previstos. En tal caso, el acto administrativo debe ser corregido para adecuarse a la realidad. Así la Administración podrá: i) Declarar la invalidez del acto por haberse incurrido en algún vicio de legalidad. Si los hechos no eran efectivos al momento de dictarse el acto administrativo, este carece de causa. ii) Declarar el decaimiento del acto por haberse producido hechos sobrevinientes que lo hacen imposible. iii) Modificar el acto administrativo, Sin embargo, se debe considerar que estas medidas son excepcionales. iv) Declarar el incumplimiento del PdC, por el incumplimiento de las obligaciones contraídas en él. Sobre estas dos últimas opciones ahondaremos más adelante.

\section{d. Los efectos que deben ser descritos en el PdC}

\section{i. Los efectos a describir}

En principio el PdC debe incluirse todos aquellos efectos que recaigan sobre el medio ambiente o en la salud de las personas, que consten en la etapa preliminar o los que son comunicados al momento de resolver. Desde que estos son incorporados en la resolución que aprueba el PdC la SMA los hace propios, por lo que serán examinados en una eventual revisión de legalidad.

ii. La carga de la prueba

La resolución que aprueba el $\mathrm{PdC}$ persigue una finalidad colaborativa y no represiva, buscando la restitución de la legalidad, lo que implica que es necesario señalar metas y acciones que se deriven de la normativa ambiental. En

\footnotetext{
99 Segundo Tribunal Ambiental. Sociedad Contractual Minera Corporación de Desarrollo del Norte con Superintendencia del Medio Ambiente (2017), cons. 44. (Rol N R-82-2015 [acumulada con R-100-2016 y R-119-2016]).
} 
tal sentido, la carga de probar los efectos sobre el medio ambiente, y la utilidad de las acciones para alcanzar un cumplimiento de la normativa ambiental corresponde ante todo al presunto infractor, que es el titular del proyecto o iniciativa ${ }^{100}$. En efecto, el literal a) del artículo 7 del D.S. № 30 de 2012 prevé que el titular de un proyecto debe desarrollar en su PdC la descripción de los hechos, actos u omisiones que constituyen la infracción en que se ha incurrido, así como de sus efectos. Mientras más acento se ponga en las acciones, la SMA más se hace responsable de lo resuelto.

Con todo, la jurisprudencia del Segundo Tribunal Ambiental ha puntualizado que es deber de la SMA exigir al titular del proyecto mayores antecedentes para descartar la presencia de efectos negativos ambientales a consecuencia de los incumplimientos, y no al reclamante:

no se está exigiendo que se realicen 'ejercicios imposibles para levantar relaciones de causalidad', sino que, simplemente, requerir al titular - dada la naturaleza de los incumplimientos- argumentos y fundamentos técnicos suficientes que permitan razonablemente entender por qué no se produjeron efectos negativos con dichos incumplimientos, cuando lo esperable era que sí se produjeran [...] Se trata, por tanto, de un deber que recae directamente en la SMA, quien debe velar porque el programa de cumplimiento aprobado cumpla con la función de protección al medio ambiente, motivo por el cual no corresponde al reclamante de autos - dada las características de los incumplimientos imputados- acreditar que se presentaron efectos negativos por los incumplimientos contenidos en la formulación de cargos ${ }^{101}$.

La Corte Suprema al fallar los recursos de casación interpuestos en contra de esta sentencia afirmó que:

es el sujeto pasivo del procedimiento administrativo sancionador quien debe incorporar en el PdC todos los antecedentes que permitan a la autoridad establecer la veracidad de su afirmación respecto de la inexistencia de efectos, toda vez que es él quien pretende eximirse de la imposición de una sanción ${ }^{102}$.

Igualmente, el Primer Tribunal Ambiental ha estimado que si bien la SMA -al aprobar un PdC- tiene discrecionalidad para evaluar la información proporcionada por el presunto infractor, el no considerar la opinión de otros órganos de la Administración del Estado con competencia ambiental puede resultar en una decisión infundada ya que:

100 Segundo Tribunal Ambiental. Pastene con Superintendente del Medio Ambiente (2017), cons. 27 y 38. (Rol No 104-2016.)

101 Ibíd., cons. 39-40.

102 Corte Suprema. Pastene con Superintendencia del Medio Ambiente (2018), cons. 13 (Rol No 11.485-2017). 
la carencia de una visión sectorial, como la que aportan estos servicios públicos [SAG, CONADI y DGA], restringiendo la competencia especifica técnico-legal y debida coordinación de estos para realizar una evaluación integral y sistémica de los efectos, acciones y metas que se especifican en el $\mathrm{PdC}$ propuesto y aprobado ${ }^{103}$.

Cabe agregar que, la judicatura medioambiental ha señalado en diversas oportunidades que la presentación de un programa de cumplimiento no constituye un mecanismo de autoincriminación del supuesto infractor, toda vez que la LOSMA no exige (tampoco lo hace el D.S. № 30 de 2012) como requisito para la presentación de un $\mathrm{PdC}$ que el regulado acepte responsabilidad, la cual deberá determinarse en el procedimiento sancionatorio respectivo ${ }^{104}$.

\section{Caminos que puede tomar la SMA frente al cambio de circunstancias}

Como ya adelantamos, la SMA podrá declarar la invalidez del acto por haberse incurrido en algún vicio de legalidad; declarar el decaimiento del acto por haberse producido hechos sobrevinientes que lo hacen imposible; modificar el acto administrativo que aprueba un $\mathrm{PdC}$; y declarar el incumplimiento del PdC, por el incumplimiento de las obligaciones contraídas en él. Con todo, profundizaremos en los dos últimos caminos, atendido que la fundamentación técnico-ambiental y jurídica de las respectivas resoluciones presenta mayores dificultades y puede ser de mayor complejidad que las otras. A nuestro juicio, es preferible optar por modificar la resolución que aprueba un $\mathrm{PdC}$, atendiendo a una interpretación finalista del artículo 42 de la LOSMA, en el sentido de dotar de eficacia al mecanismo de incentivo al cumplimiento creado por el legislador. Además, no es baladí considerar los recursos públicos que se han destinados a la satisfacción de un interés público, que en este caso se trata de la protección del medio ambiente, necesarios para la adopción de una resolución que aprueba un PdC. Por último, y vinculado a lo anterior, es relevante el principio de conservación de los actos administrativos, que "obliga a conservar todos aquellos actos que sean capaces de cumplir con su finalidad, incluso en el supuesto de que hayan incurrido en alguna ilegalidad, siempre lógicamente, que la ilegalidad cometida no vulnere algunos de los intereses que el Derecho tiene encomendado proteger" ${ }^{\prime \prime 25}$.

\footnotetext{
103 Primer Tribunal Ambiental. Asociación Indígena Aymara Salar de Coposa con Superintendencia del Medio Ambiente (2019), cons. 205. (Rol N R-25-2019).

104 Segundo Tribunal Ambiental. Compañía Minera Nevada SpA con Superintendencia del Medio Ambiente (2016), cons. 17 (Rol No R-75-2015); Sociedad Contractual Minera Corporación de Desarrollo del Norte con Superintendencia del Medio Ambiente (2017), cons. 31 (Rol No R-822015 [acumulada con R-100-2016 y R-119-2016]); López con Superintendencia del Medio Ambiente (2018), cons. 20 (Rol N R-163-2016).

105 Beladiez 1994, 69.
} 


\section{a. Modificación}

En principio es posible afirmar que es un presupuesto de la resolución que aprueba un programa de cumplimiento la efectividad de los supuestos de hecho que le sirven de fundamento. Por lo tanto, si cambian las circunstancias, se debe modificar el instrumento ${ }^{106}$. La modificación es, técnicamente, una revocación parcial del acto administrativo y se le deben aplicar las mismas reglas ${ }^{107}$. La cuestión, en el derecho comparado está cruzada por la discusión de si es posible o no incluir una reserva de modificación en el acto administrativo ${ }^{108}$, como cláusula accesoria del mismo.

Resulta discutible la pertinencia de incluir en la resolución que aprueba un PdC cláusulas de reserva de modificación explícitas. Si bien por una parte tienen la ventaja de que facilitan la dictación de un acto administrativo modificatorio, por otra parte, generan nuevos problemas. Por de pronto, pueden ser impugnadas, con lo que demoraría la adopción que un instrumento que ha de ser más eficiente que la tramitación del procedimiento sancionador. Además, puede que sean incompatibles con el interés público en el caso concreto. Es necesario puntualizar que la Guía para la presentación de Programas de Cumplimiento por infracciones a instrumentos de carácter ambiental, de la SMA contempla la posibilidad de identificar "impedimentos", los cuales pueden ocasionar la imposibilidad de ejecutar alguna acción comprometida por el titular del proyecto en el $\mathrm{PdC}^{109}$. Se distinguen dos tipos, aquéllos que resultan en el retraso o suspensión temporal de la ejecución de la acción, y aquéllos impeditivos, que determinan la imposibilidad continuar con la acción comprometida. Para esto últimos, el titular debe comprometer acciones alternativas. En relación con el acontecimiento de hechos imprevistos para el cumplimiento de la acción del PdC, la SMA ordena informar a la autoridad sobre estas, para su ponderación en los reportes que deben presentarse, según los medios de verificación ${ }^{110}$.

Si, como se ha dicho, el acto administrativo que aprueba o rechaza el $\mathrm{PdC}$ es discrecional, no existe una obligación de modificarlo. Así se ha entendido, en el derecho español que nuestra LBPA sigue de forma muy cercana:

[A] unque los casos en que procede la modificación, están regulados en la Ley o son impuestos directamente por la resolución administrativa, corresponde a la Administración su apreciación: en ningún caso su concurrencia produce efectos ipso iure, sino que debe ser declarada por la Administración ${ }^{111}$.

\footnotetext{
106 Desde el punto de vista de la eficacia del acto administrativo la modificación es una manera de evitar su decaimiento, esto es, que se extinga porque un cambio de circunstancias lo hizo imposible. Caldera 1979, 192-193.

107 VeLASCO 1996, 186-187.

108 Maurer 2011. Op. Cit. 325.

109 Superintendencia del Medio Ambiente 2018, 16.

110 Ibíd.,17.

111 Gallego y Menéndez 2001, 116.
} 
Enseguida, cabe preguntarse cuál es el efecto que tiene la modificación. Ello depende de si el acto que aprueba el PdC es un acto favorable o desfavorable. Como hemos dicho antes, desde el punto de vista de las cláusulas que contiene el $\mathrm{PdC}$ es un acto administrativo desfavorable, sin embargo:

[D]esde el punto de vista del interés del ciudadano lo decisivo no es si el acto modificado es favorable o desfavorable, sino si la modificación le afecta favorable o desfavorablemente... la modificación perjudicial para el ciudadano de un acto desfavorable tiene el mismo efecto que la revisión de oficio o la revocación de un acto administrativo favorable, y análogamente en el caso de la modificación beneficiosa de un acto favorable, que afecta al ciudadano ampliando sus derechos, procede aplicar las reglas sobre la revisión de oficio [invalidación] y la revocación de actos administrativos desfavorables ${ }^{112}$.

De este modo, por una parte, si la modificación es favorable, es decir, menos gravosa que el PdC originalmente aprobado, en principio es posible afirmar que es una decisión discrecional de la Administración ${ }^{113}$. Es posible prever que, en este caso, será el presunto infractor quien le propondrá a la SMA la modificación.

Ahora bien, cabe preguntarse qué pasa si la Administración ha efectuado actos que han confirmado lo actuado por el proponente. Según parte de la doctrina la modificación puede llegar a ser obligatoria ${ }^{114}$. Ahora bien, esa confirmación requiere una manifestación de voluntad inequívoca por parte de la Administración, y el simple conocimiento no causa esa obligación si no está acompañada de actos positivos.

Por otra parte, si la modificación es desfavorable, es decir, impone medidas más gravosas que el PdC en curso, la doctrina propone un test de ponderación entre legalidad, es decir, la obligación de restituir el cumplimiento de la normativa ambiental, y la confianza legítima del presunto infractor, que tiene una expectativa (no derecho subjetivo porque el particular no tiene derecho a la ilicitud) a que la Administración respete su resolución ${ }^{115-116}$. La práctica demuestra que la SMA ha estado abierta a modificar sus propios actos, por ejemplo, la jurisprudencia señaló:

el 12 de agosto de 2016, mediante resolución exenta Nº7/Rol D-0182016, la SMA aprobó el programa de cumplimiento presentado por Codelco, corrigiéndolo de oficio en varios puntos, tal como se señala específicamente en el Resuelvo III de la citada resolución. El 19 de agosto de

\footnotetext{
112 Maurer 2011. Op. cit., 307.

113 Ibíd. Op. cit., 331.

114 Ibíd.

115 Ibíd., 326-327.

116 Velasco, 160-161.
} 
2016, la SMA complementó la resolución exenta № 7, incorporando en la sección 11.4, algunos impedimentos y acciones en caso de ocurrencia ${ }^{117}$.

\section{b. Resolución que declara el cumplimiento o incumplimiento del PdC}

En virtud de lo señalado en el artículo 42 LOSMA en relación con el artículo 12 DS 30/2013, el cumplimiento satisfactorio del PdC originará la extinción del procedimiento administrativo sancionador, lo que debe ser declarado por la SMA a través de una resolución ${ }^{118}$ La resolución que declara el incumplimiento del PdC, técnicamente, lo que hace es declarar que la resolución que lo aprobó "caducó" por el incumplimiento por su destinatario de los deberes que imponía"119.

En relación con ello, cabe preguntarse, en primer lugar, si puede dividirse el acto que declara el cumplimiento. En principio la respuesta debe ser negativa. Si bien la sanción administrativa es la ultima ratio -lo que nos llevaría a pensar que debe evitarse por todos los medios posibles una resolución sancionatoria- una vez que las obligaciones son fijadas por la resolución de aprobación, hay sujeción estricta a ella, tanto para la SMA como para el proponente. Esta conclusión se apoya en que el inciso sexto del artículo 42 LOSMA señala que para declarar satisfactoriamente cumplido el PdC este debe cumplirse "en los plazos establecidos y de acuerdo con las metas fijadas en él". Además, el DS 30/2013 hace más explícito esta condición al señalar: "una vez implementadas íntegramente cada una de las acciones" (artículo 11), y "de acuerdo con las metas fijadas en el" (artículo 12). Ahora bien, este criterio puede flexibilizarse en el siguiente sentido. Lo que justifica el levantamiento de la sanción es el cumplimiento de las metas, es decir, del objetivo. De este modo, no tendría sentido aplicar la sanción si, no obstante que las acciones del PdC no se observaron estrictamente, de todos modos, se lograron las metas ${ }^{120}$.

En segundo lugar, cabe preguntarse si, no obstante, la aprobación de un $\mathrm{PdC}$ puede el presunto infractor seguir adelante con su actividad. Lo cierto es que, por definición, el PdC significa que no hay cumplimiento inmediato. Habrá un periodo de tolerancia, definido por la SMA. Ello es una consecuencia del hecho que el PdC esté sometido a un plazo. Antes de que ese plazo esté cumplido existirá un incumplimiento (parcial) de la normativa ambiental hasta llegar a un cumplimiento total. En todo caso, la aprobación del PdC no es un título habilitante nuevo, que autorice al presunto infractor a cometer nuevas ilicitudes 0 a realizar actividades que deben someterse a otro tipo de controles administrativos o ambientales. Así, el presunto infractor debe sujetarse a la normativa ambiental aplicable. Además, debe "contener" los efectos de su

\footnotetext{
117 Segundo Tribunal Ambiental. León con Superintendencia del Medio Ambiente (2017), vistos, 6. (Rol No R-132-2016).

118 Caldera 1979, 184, 187 y 189.

119 Ibíd., 212.

120 Arancibia 2014, 129-147, esp. 133.
} 
infracción. En este sentido, el PdC habilita a realizar todas las actividades que sean necesarias para "conservar" las instalaciones del presunto infractor. De ese modo podrá impedir que los efectos se propaguen. La ley no autoriza a que por acto de la SMA se deterioren las instalaciones.

En tercer lugar, cabe preguntarse qué ocurre si la infracción es no entregar información y al entregarla se detectan incumplimientos de fondo. La respuesta es que existirá, entonces, una pluralidad de procedimientos. Ello, porque tienen causas diferentes. Por lo tanto, corresponde efectuar una nueva formulación de cargos dará origen a un procedimiento separado.

\section{Conclusiones}

Existen diferentes factores que hacen del PdC un instrumento sensible al cambio de circunstancias. Primero, la falta de certeza acerca de los efectos de la infracción ambiental, especialmente, la visión parcial que se tiene en ese momento de cómo se desencadenaron los cursos causales. Segundo, el hecho de que el instrumento se ejecutará a lo largo de un determinado plazo que puede llegar a ser de varios años de duración. Tercero, las asimetrías de información. Con todo, para reconocer el advenimiento de condiciones nuevas e imprevistas de carácter sustancial durante la ejecución del PdC, se debe atender a la eficacia como criterio esencial. Dicho criterio se preocupa específicamente de enfrentar los efectos del incumplimiento ambiental imputado al presunto infractor, considerando que el plan de acciones y metas sean eficaces para cumplir con la normativa ambiental y medidas para reducir o eliminar los efectos negativos generados por el incumplimiento. No puede tolerarse un $\mathrm{PdC}$ que agrava la situación previa.

Para ponderar el criterio de efectividad en la aprobación de un $\mathrm{PdC}$ se exige un nivel de certeza menor a la sanción o al dictamen del instructor, además, la carga de probar los efectos sobre el medio ambiente, y la utilidad de las acciones para alcanzar un cumplimiento de la normativa ambiental corresponde al presunto infractor, que es el titular del proyecto o iniciativa. La evidencia para probar la concurrencia o no de los efectos negativos al medio ambiente podrá existir como indiciaria al momento de la formulación de cargos, ya que no es posible contar con pruebas concretas pues no se ha verificado la etapa de instrucción del procedimiento donde dicha prueba se rinde. En cambio, antes de la aprobación de un PdC dicho estándar se eleva por cuanto se abre una fase de colaboración recíproca entre el presunto infractor y la SMA.

Una vez aprobado un $\mathrm{PdC}$ puede ocurrir que el desenvolvimiento de los efectos de la infracción sea distinto a los previstos. En tal caso, el acto administrativo debe ser corregido para adecuarse a la realidad. Así la Administración podrá: i) Declarar la invalidez del acto por haberse incurrido en algún vicio de legalidad. Si los hechos no eran efectivos al momento de dictarse el acto administrativo, este carece de causa; ii) Declarar el decaimiento del acto por haberse producido hechos sobrevinientes que lo hacen imposible; 
iii) Modificar el acto administrativo.; y iv) Declarar el incumplimiento del PdC, por no cumplir con las obligaciones contraídas en él.

Particularmente, para los dos últimos casos, en caso de que se apruebe la modificación del acto que aprueba el $\mathrm{PdC}$, debe distinguirse si la modificación es favorable o no para el regulado. Si la modificación es favorable, es decir, menos gravosa que el PdC originalmente aprobado, en principio es posible afirmar que es una decisión discrecional de la Administración. Por otra parte, si la modificación es desfavorable, es decir, impone medidas más gravosas que el $\mathrm{PdC}$ en curso, la doctrina propone un test de ponderación entre legalidad, es decir, la obligación de restituir el cumplimiento de la normativa ambiental, y la confianza legítima del presunto infractor, que tiene una expectativa (no derecho subjetivo porque el particular no tiene derecho a la ilicitud) a que la Administración respete su resolución. También la SMA podrá dictar una resolución que declara el incumplimiento del PdC, técnicamente, lo que hace es declarar que la resolución que lo aprobó "caducó" por el incumplimiento por su destinatario de los deberes que imponía.

\section{Bibliografía citada}

Armstrong, K., y KilPATRICK, C. (2006). Law, governance, or new governance-the changing open method of coordination. Columbia Journal of European Law, 13 (3), pp. 649-677.

Arancibia MatTAR, J. (2014). El principio de necesidad de la sanción administrativa como potestad de ultima ratio (pp. 129-147). En J. Arancibia Mattar y P. Alarcón (Coord.), Sanciones Administrativas X Jornadas de Derecho Administrativo. Editorial Thomson Reuters.

BARros Bourie, E. (2006). Tratado de responsabilidad extracontractual. Editorial Jurídica de Chile.

Beladiez Rojo, Margarita (1994). Validez y eficacia de los actos administrativos. Marcial Pons

Bermúdez, J. (2014a). Derecho Administrativo General. (3era ed.). Thomson Reuters/Legal Publishing.

Bermúdez Soto, J. (2014b). Fundamentos de Derecho Ambiental (2 ${ }^{\text {da }}$ ed.). Ediciones Universitarias de Valparaíso.

Bocanegra, R. (2006). Lecciones sobre el Acto Administrativo (3 ${ }^{a}$ ed.). Thomson Reuters/ Aranzadi.

Biblioteca del Congreso Nacional de Chile (2010). Historia de la Ley No 20.417, Crea el Ministerio, el Servicio de Evaluación Ambiental y la Superintendencia de Medio Ambiente. https://www.bcn.cl/historiadelaley/historia-de-la-ley/vista-expandida/4798/.

BLACK, J. (2006). What is regulatory innovation? En J. Black, M. Lodge y M. Thatcher (Eds.), Regulatory innovation: a comparative analysis (pp. 1-15). Edward Elgar Publishing.

Caldera, H. (1979). Manual de Derecho Administrativo. Editorial Jurídica de Chile.

Cordero VegA, L. (2015). Lecciones de Derecho Administrativo (2 ${ }^{\mathrm{a}}$ Ed.). Legal Publishing Chile.

De Sadeleer, N. (2002). Environmental Principles: From Political Slogans to Legal Rules. Oxford University Press.

FISHER, E. (2013). Environmental Law as 'Hot' Law. Journal of Environmental Law, 2 5(3), 349-351.

Fisher, E., Lange, B. y Scotford, E. (2019). Environmental law: Text, cases \& materials ( $2^{\mathrm{a}} \mathrm{Ed}$.). Oxford University Press.

Gallego, A. y Menéndez, Á. (2001). Acto y Procedimiento Administrativo. Marcial Pons.

GunNINGHAM, N. (2009). Environment law, regulation and governance: Shifting architectures. Journal of Environmental Law, 29 (2), 179-212. 
Hervé Espejo, D. y Plumer Bodin, M. (2019). Instrumentos para una intervención institucional estratégica en la fiscalización, sanción y cumplimiento ambiental: el caso del programa de cumplimiento. Revista de Derecho (Concepción), 87 (245), 11-49.

HuERGo, A. (2007). Las sanciones administrativas. lustel.

Hunter Ampuero, I. (2014). Legitimación activa y los Tribunales Ambientales (Segundo Tribunal Ambiental). Revista de Derecho (Valdivia), 27 (1), 259-270.

IsHWARA BHAT, P. (2019). Idea and Methods of Legal Research. Oxford University Press.

LeE, M. (2014). EU Environmental Law, Governance and Decision-Making (2 ${ }^{\mathrm{a}}$ Ed.) Hart Publishing.

LIVERMORE, M. (2007). Reviving environmental protection: preference-directed regulation and regulatory ossification. Virginia Environmental Law Journal, 25 (3), 311-386.

LORENTE HURTADO, F. (2008). La terminación convencional en los procedimientos sancionadores nacionales. En S. Martínez Lage y A. Petitbò Juan (Dir.), Remedios y sanciones en el derecho de la competencia (pp. 163-178). Marcial Pons.

Maurer, H. (2011[2009]). Derecho Administrativo. Parte General (G. Doménech Pascual, trad.). Marcial Pons.

Ossandón Rosales, J. (2015). Incentivos al Cumplimiento Ambiental. Editorial Libromar.

Pedersen, O. (2013). Environmental enforcement undertakings and possible implications: Responsive, smarter or rent seeking? The Modern Law Review, 76 (2), 319-345.

Preston, B. (2019). Regulatory Organization. En E. Lees y J. Viñuales (Eds.), The Oxford Handbook of Comparative Environmental Law (pp. 718-748). Oxford University Press.

RHodes, R. (1996). The New Governance: Governing without Government. Political Studies, 44 (4), pp. 652-667.

Soto Delgado, P. (2016). Sanciones administrativas como medidas de cumplimiento del Derecho: un enfoque funcional y responsivo aplicado al régimen sancionatorio ambiental. lus et Praxis, 22 (2), 189-226.

Superintendencia del Medio Ambiente (2018). Guía para la presentación de programas de cumplimiento por infracciones a instrumentos de carácter ambiental. https://portal.sma. gob.cl/index.php/portal-regulados/instructivos-y-guias/programa-de-cumplimiento/

TAPIA, M. (2020). Caso fortuito o fuerza mayor ( $3^{a}$ Ed.). Thomson Reuters.

VelAsCo, F. (1996). Las cláusulas accesorias del acto administrativo. Tecnos.

\section{Normativa citada}

Ley $N^{\circ} 19.880$ de 2003. Establece bases de los procedimientos administrativos que rigen los actos de los órganos de la Administración del Estado (LBPA). 29 mayo 2003. D.O. $N^{\circ} 37.564$.

Ley № 20.417 de 2010. Crea el Ministerio, el Servicio de Evaluación Ambiental y la Superintendencia del Medio Ambiente (LOSMA). 26 enero 2010. D.O. N 39.558.

Decreto supremo No 30 de 2013 [Ministerio del Medio Ambiente]. Aprueba Reglamento sobre Programas de Cumplimiento, Autodenuncia y Planes de Reparación. 11 febrero 2013.

Decreto $N^{\circ} 1$ de 2000 [con fuerza de ley]. Fija texto refundido, coordinado y sistematizado de la Ley N 18.575, Orgánica Constitucional de Bases Generales de la Administración del Estado (LOCBGAE). 17 de noviembre de 2001. D.O. N 36.850.

\section{Jurisprudencia citada}

Corte Suprema. Tercera Sala. Rol No 67.418-2016; 3 de julio de 2017.

Corte Suprema. Tercera Sala. Rol No 11.485-2017; 5 de marzo de 2018.

Corte Suprema. Tercera Sala. Rol No 8.456- 2017; 22 de mayo de 2018.

Corte Suprema. Tercera Sala. Rol No 16.328-2018. 30 de octubre de 2018.

Primer Tribunal Ambiental. Rol Nº R-4-2018; 6 de junio de 2018. Sentencia firme o ejecutoriada. 
Primer Tribunal Ambiental. Rol N R-17-2019; 26 de diciembre de 2019. Sentencia firme o ejecutoriada.

Primer Tribunal Ambiental. Rol N R-25-2019; 30 de diciembre de 2019. Sentencia firme o ejecutoriada.

Primer Tribunal Ambiental. Rol No R-21-2019; 27 de octubre de 2020. Sentencia firme o ejecutoriada.

Segundo Tribunal Ambiental Rol No R-6-2013; 3 de marzo de 2014. Sentencia firme o ejecutoriada, salvo en lo referido a la comparecencia en el proceso de reclamación como tercero coadyuvante de la Compañía Minera Nevada SpA. Corte Suprema. Tercera Sala. Rol No 11.600-2014. 30 de diciembre de 2014.

Segundo Tribunal Ambiental. Rol No R-68-2015; 27 de julio de 2016. Sentencia firme o ejecutoriada. Corte Suprema. Tercera Sala. Rol No 58.986- 2016. 17 de julio de 2017.

Segundo Tribunal Ambiental. Rol N R-75-2015; 30 de diciembre de 2016. Sentencia firme o ejecutoriada.

Segundo Tribunal Ambiental. Rol N R-112-2016; 2 de febrero de 2017. Sentencia firme o ejecutoriada. Corte Suprema. Tercera Sala. Rol No 8.456- 2017. 22 de mayo de 2018.

Segundo Tribunal Ambiental, Rol No 104-2016; 24 de febrero de 2017. Sentencia firme o ejecutoriada. Corte Suprema. Tercera Sala. Rol N 11.485-2017; 5 de marzo de 2018.

Segundo Tribunal Ambiental. Rol No R-116-2016; 28 de junio de 2017. Sentencia firme o ejecutoriada. Corte Suprema. Rol N³6.202-2017. 06 de noviembre de 2017.

Segundo Tribunal Ambiental. Rol No R-82-2015 (acumulada con R-100-2016 y R-119-2016); 29 de septiembre de 2017. Sentencia firme o ejecutoriada.

Segundo Tribunal Ambiental. Rol N R-132-2016; 20 de octubre de 2017. Sentencia firme o ejecutoriada.

Segundo Tribunal Ambiental. Rol No R-163-2016; 29 de junio de 2018. Sentencia firme o ejecutoriada.

Segundo Tribunal Ambiental. Rol No R-160-2017; 21 de agosto de 2018. Sentencia firme o ejecutoriada. Corte Suprema. Rol No 24.870-2018. 17 de diciembre de 2019.

Segundo Tribunal Ambiental. Rol No R-153-2017; 14 de septiembre de 2018. Sentencia firme o ejecutoriada.

Segundo Tribunal Ambiental. Rol N R-170-2018; 29 de abril de 2020. Sentencia firme o ejecutoriada.

Segundo Tribunal Ambiental. Rol N R-199-2018; 11 de agosto de 2020. Sentencia firme o ejecutoriada.

Tercer Tribunal Ambiental. Rol No R-36-2016; 19 de agosto de 2016. Sentencia firme o ejecutoriada. Corte Suprema. Rol No 67.418-2016. 3 de julio de 2017.

Tercer Tribunal Ambiental. Rol No R 28-2016; 28 de noviembre de 2016. Sentencia firme o ejecutoriada. Corte Suprema. Rol No 177-2017. 3 de octubre de 2017.

Tercer Tribunal Ambiental. Rol No R-40-2016; 23 de diciembre de 2016. Sentencia firme o ejecutoriada. 